\title{
A Huge Schwannoma of Superficial Fibular Nerve (A Case Report)
}

\author{
Chafik H*, Maanouk R, Krite A, Elmarfi A, Abid H, El Idrissi M, El Ibrahimi A, El Mrini A
}

Service de Chirurgie ostéo-articulaire B4, CHU Hassan II. Fès, Marocco

DOI: $\underline{10.36347 / \mathrm{sasjs} .2020 . \mathrm{v} 06 \mathrm{i} 03.017}$

| Received: 03.03.2020 | Accepted: 15.03.2020 | Published: 24.03 .2020

*Corresponding author: Dr. Chafik Hachem

Abstract

Case Report

Schwannomas are benign and the most common nerve tumors. They are frequent in the upper limb, preferably affecting the brachial plexus. In the lower limb, the trunk of the sciatic nerve and the common fibular nerve seems to be the most affected. We report a case of an unusual superficial fibular nerve schwannoma. The diagnosis is based on the suggestive MRI aspect, but it's histology that confirms it. Surgical treatment by enucleation with respecting nerve's fibers allows healing. The rate of recurrence and degeneration is very low for this kind of tumor.

Keywords: Schwannomas, nerve tumors, limb, MRI aspect.

Copyright @ 2020: This is an open-access article distributed under the terms of the Creative Commons Attribution license which permits unrestricted use, distribution, and reproduction in any medium for non-commercial use (NonCommercial, or CC-BY-NC) provided the original author and source are credited.

\section{INTRODUCTION}

Benign tumors of the peripheral nerves account for $2 \%$ of the soft-tissue tumors, $80 \%$ are represented by schwannomas. Although they represent the commonest benign peripheral nerve sheath tumors, the occurrence on the lower limbs account for $1 \%$ of all cases [1]. Reports of Schwannomas arising specifically from the superficial fibular nerve are exceptionally rare [2]. We report a case of huge superficial fibular nerve schwannoma in a 34-years-old woman and we insist on its clinical, radiological and therapeutic features.

\section{A CASE PRESENTATION}

A 34 years old woman, with no medical history. She complained for 8 months history of a gradually growing lump at her lower leg, with a leg pain and numbness on the anterolateral side of her left leg, it irradiated distally to the dorsal side of the ankle and foot. These pains become worse by the effort.

The physical examination revealed a firm mass in the lower lateral of her left leg, measuring $6 \mathrm{~cm} * 4$ $\mathrm{cm}$, located on the subcutaneous plane with little mobility in the coronal plane, Tinel sign was positive in the territory of the superficial fibular nerve.
Electromyography (EMG) confirmed the fibullar nerve involvement with decreased amplitude of sensory potentials

The MRI showed a well limited homogeneous lesion centered on the superficial fibular nerve in hypointense signal in $\mathrm{T} 1$, and hyperintense signal in $\mathrm{T} 2$ which increases after injection of gadolinium (Figure$1)$.

A surgical resection of the tumor was decided by an external approach of the leg, the careful dissection allowed a one-piece resection of the tumor which was at the expense of the superficial fibular nerve; the tumor was easily extirpated without interruption of the nervous fibers (Figure-2).

Histological examination showed fusiform cells arranged in wavy bays. They are provided with regular elongate ovoid nuclei arranged in blanks of palisades with rolls or nodules (Figure-3).

The postoperative period was uneventful, the initial symptoms disappeared and no added neurological sign was observed. Six months later, the patient didn't complain no pain neither neurological symptom. 

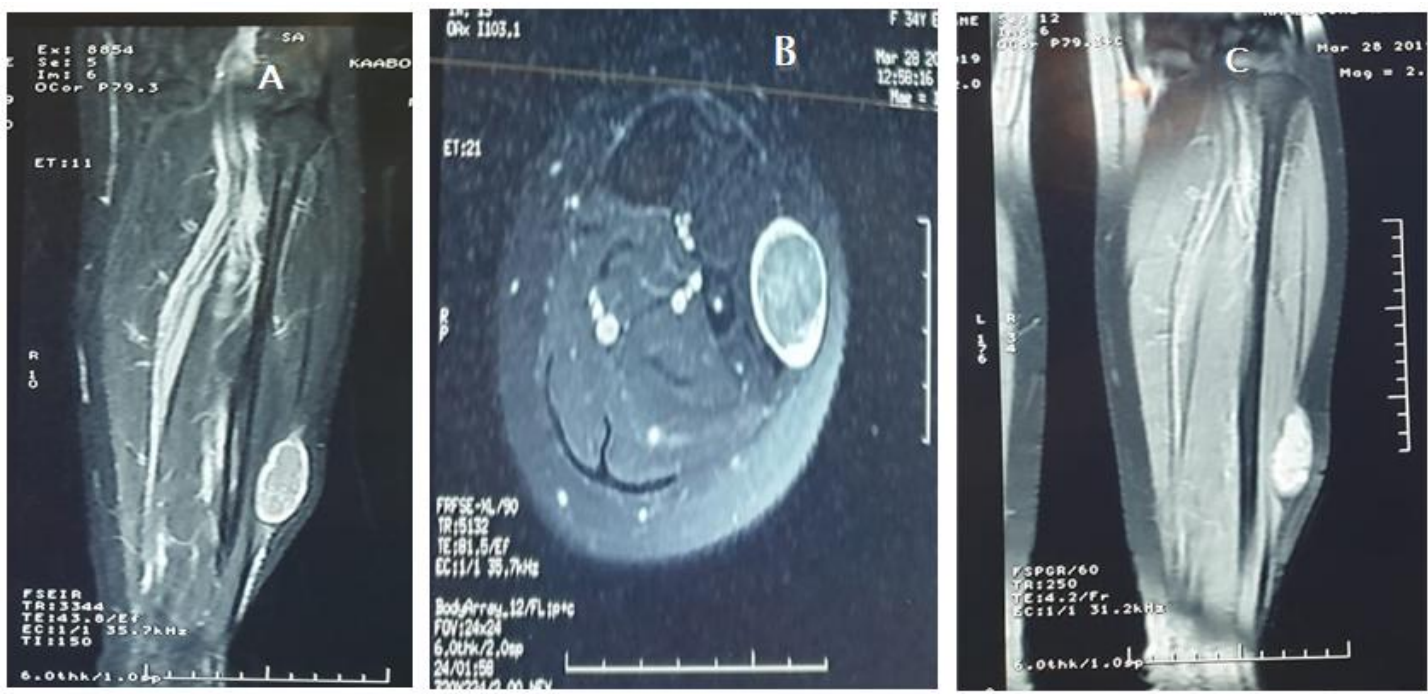

Fig-1: MRI of the patient's left leg showing fusiform mass centered on the fibular superficial nerve with contrast-enhanced T1-weighted hyposignal (A) sagital view on T1, (B) Axial view on T1 and T2-weighted hypersignal (C) sagital view on T2
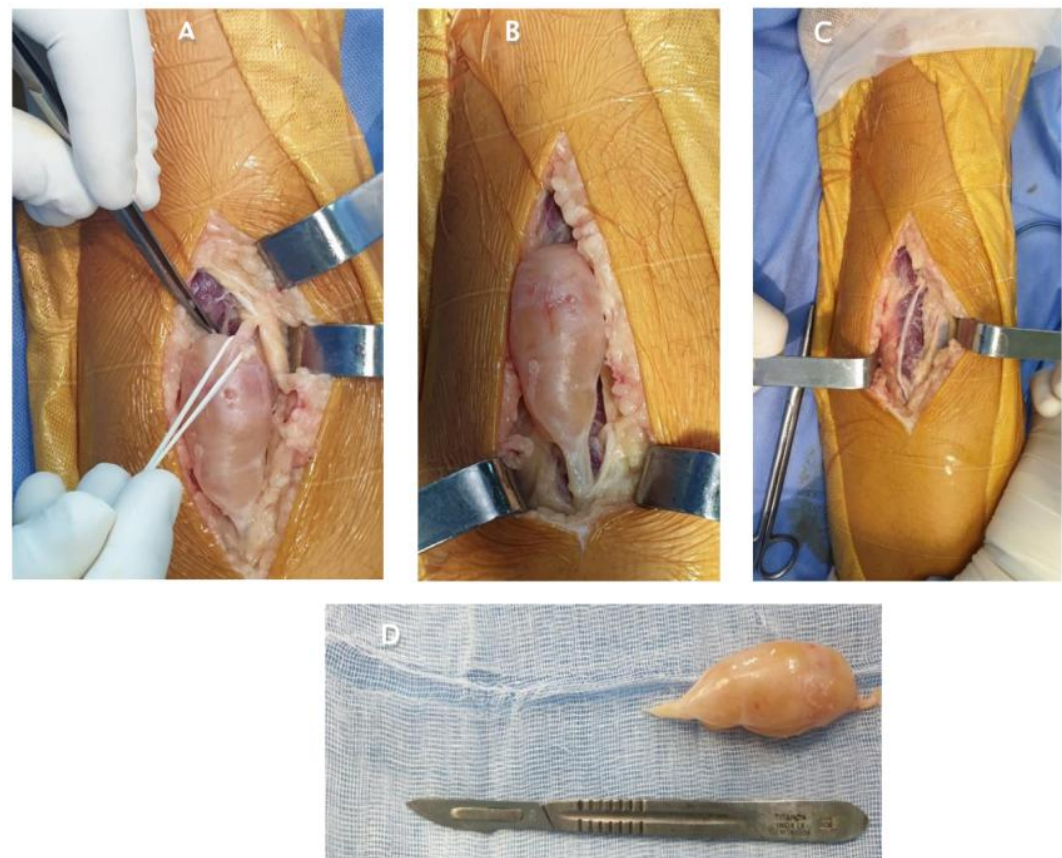

Fig-2: Surgical excision of the patient's left leg tumor. (A,B) lateral approach with tumoral exposure. (C) Perineural dissection and tumoral detachment of the nerve sheath. (D) the resected lesion measures

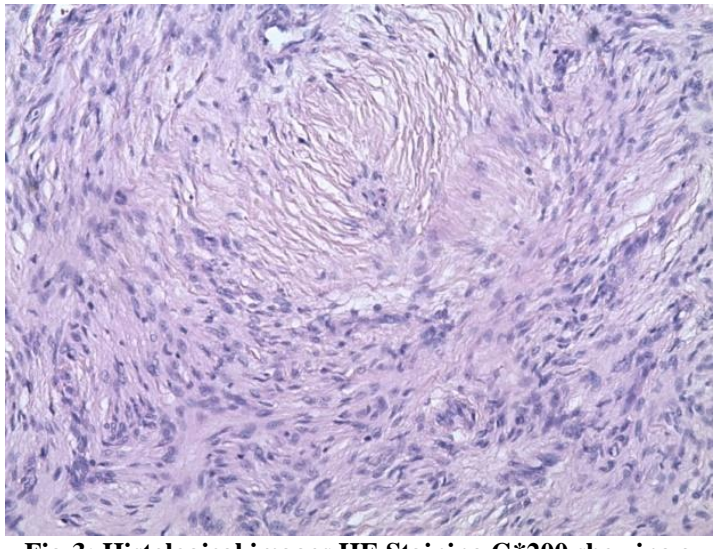

Fig-3: Histological images HE Staining G*200 showing a proliferation of fusiform fused cells with palisade nuclear disposition

\section{DISCUSSION}

Schwannomas were described for the first time in the XIX century, they can occur at all ages, but especially between 30 and 60 years, with a sex ratio of 1 [3]. They are frequent in the upper limb, preferably affecting the brachial plexus. In the lower limb, the trunk of the sciatic nerve and the common fibular nerve seems to be the most affected [1]. Regardless the tumor location, an clinical examination looks for pain, a lump and its characteristics, and neurological symptom (paresthesia) [1, 4].

Allied to the fact that they have a slowgrowing pattern, they never traverse through the nerve but remain in the sheath lying on top of it. This explains 
why they are usually clinically silent and present oftentimes as an incidental finding.

Including electromyography (EMG) and nerve conduction study (NCS), evaluate neuromuscular function to assess denervation, preservation of motor units, or conduction loss [5].

MRI can guide the diagnosis by showing an aspect in favor of schwannoma. It can show in T1 a signal of the same intensity or slightly higher than the muscle, in T2 a hyper-intense signal sometimes a "target image" with a hyper-intense peripheral halo and a hypo-intense center [6]. The confirmation of the diagnosis remains histological [7]. On microscopic analysis, Schwannomas appear solid or cystic and exhibit specific patterns: the Antoni A type has a spindle-cell array with collagen matrix arranged into palisading Verocay bodies; The Antoni B pattern exhibits a looser structure of mucinous matrix with a few interspersed spindle cells; cellular Schwannomas display unusual high cellular density and nuclear, but contain few mitotic figures than malignant Schwannomas [5]. The optimal treatment is surgical excision $[8,9]$, since it is an easily extirpable tumor. After complete excision, there is no recurrence. The malignant degeneration of schwannoma is controversial. No case of malignant degeneration has been described. In our case, the excision was complete without any local recurrence.

\section{CONCLUSION}

Benign schwannoma located at the level of the lower limbs is rare and pose a real problem of diagnosis. Histology as well as imaging is tools that allow the diagnosis of this entity and the surgical exeresis remains the best treatment. It should always be evoked in case of a young patient who has a painful nodule or subcutaneous mass.

\section{REFERENCES}

1. Rafai MA, El Otmani H, Rafai M, Bouhaajaj FZ, Largab A, Trafeh M, Adil A, Kadiri R, Slassi I. Peroneal nerve schwannoma presenting with a peroneal palsy [Syndrome de paralysie péronière révélant un schwannome du sciatique poplité externe au col du péroné]. Rev Neurol (Paris), 2006;162(September (8-9)):866-8.

2. Shariq O, Radha S, Konan S. Common peroneal nerve schwannoma: an unusual differential for a symptomatic knee lump. Case Reports. 2012 Dec 3;2012:bcr2012007346.

3. Kehoe NJ, Reid RP, Semple JC. Solitary benign peripheral-nerve tumours. Review of 32 years' experience. The Journal of bone and joint surgery. British volume. 1995 May;77(3):497-500.

4. Chick G, Alnot JY. Silbermann-Hoffman. Tumeurs bénignes isolées des nerfs péripheriques. Rev Chir Orthop. 2000;86:131-7.

5. Rodriguez FJ, Folpe AL, Giannini C, Perry A. Pathology of peripheral nerve sheath tumors: diagnostic overview and update on selected diagnostic problems. Acta neuropathologica. 2012 Mar 1;123(3):295-319.

6. Cerofolini E, Landi A, DeSantis G, Maiorana A, Canossi G, Romagnoli R. MR of benign peripheral nerve sheath tumors. Journal of computer assisted tomography. 1991;15(4):593-597.

7. Alnot JY, Bosquet L, Cheveigné C. Tumeur primitive's des nerfs périphériques. Paris, France: Encycl-méd-chir; 1989

8. Smith W, Amis JA. Neurilemoma of the tibial nerve. A case report. JBJS. 1992 Mar 1;74(3):4434.

9. Wolock BS, Baugher WH, McCarthy EJ. Neurilemoma of the sciatic nerve mimicking tarsal tunnel syndrome. Report of a case. JBJS. 1989 Jul 1;71(6):932-4. 